\title{
EL SUJETO DE LA FISURA ESTRUCTURAL: CONSIDERACIONES ONTOLÓGICAS
}

\section{THE SUBJECT OF STRUCTURAL FISSURE: ONTOLOGICAL CONSIDERATIONS}

\author{
Manuel Martínez Herrera ${ }^{1}$ \\ manuel.martinez@ucr.ac.cr
}

Fecha de recepción: 14 junio 2016 - Fecha de aceptación: 9 enero 2017

\begin{abstract}
Resumen
El sujeto de la historia y el sujeto del inconsciente son conceptos producidos por desarrollos teóricos desarticulados. Lo cual genera, en el ámbito de las ciencias sociales, una fluctuación entre monismos estructuralistas, logocéntricos y psicoanalíticos; dicha desarticulación constituye una de las grandes deudas de las ciencias sociales. Los procesos de subjetivación, emanan de las dimensiones históricas e inconscientes constructoras de realidades. Ontológicamente, la concreción del sujeto implica una ruptura con la realidad establecida, la subjetividad tiene su origen en una ausencia absoluta que trasciende el orden societal y al propio sujeto, ubicándose más allá de la estructura social, de las posibilidades comprensivas del lenguaje, incluso, de la representación inconsciente. Desde el punto de vista ontológico, la subjetividad se constituye en un anhelo imposible e innombrable que jamás se obtura, poniendo en movimiento al sujeto y a los dominios societarios. Esta vacuidad interna, producto de las falencias y deseos humanos en pos de una plenitud perdida, encuentra, en parte, su alivio en una promesa supraterrenal. En el presente trabajo se realiza una somera revisión de algunas de las principales conceptualizaciones acerca del sujeto y de la sociedad, desde las perspectivas del marxismo y del psicoanálisis. Se abordan las posibilidades analíticas de dichas perspectivas, en función de la noción del sujeto histórico y del sujeto del inconsciente, el inconsciente entendido como acontecimiento social y la noción de acontecimiento concebida como fisura-vacuidad en el orden estructural. Es, a partir de dichas conceptualizaciones, que se propone la intelección de la subjetividad como producción social. Palabras claves: Sociedad, Subjetividad, Sujeto histórico, Sujeto del inconsciente, Estructura social.
\end{abstract}

\begin{abstract}
The subject of history and the subject of the unconscious have been concepts produced by unarticulated theoretical developments. The lack of articulation among theoretical developments has produced, in the realm of the social sciences, a fluctuation between structuralist, logocentric and psychoanalytic monisms. The articulation of both perspectives constitutes one of the great debts for the social sciences. The processes of collective subjectivity emerge from the historic and unconscious dimensions that are builders of realities. However, ontologically, the consolidation of the subject implies a fracture with the established reality, because the emergence of subjectivity finds its source in an absolute absence that transcends the social order and the subject itself, including unconscious representation. From an ontological perspective, subjectivity materializes from an impossible and unnamable longing that never seals, but that enables dynamism within the subject itself and in the social domain. The internal emptiness, produced by the humanly deficiencies and desire to pursue lost plenitude, finds, up to a certain point,
\end{abstract}

1 Escuela de Psicología, Universidad de Costa Rica, Sede Rodrigo Facio. 
relief in a heavenly promise. This article will review some of the major conceptualizations of subject and society proposed by Marxisim and Psychoanalysis. It will address the analytical possibilities of these conceptualizations based on the notion of the unconscious as a social event and that of the concept of the event as a fissure in the structural order. It is, based on the named theoretical conceptualizations, that it will propose the understanding and the analysis of subjectivity as social production.

Key Words: Society, Subjectivity, Historical subject, Subject of the unconscious, Social structure.

\section{Consideraciones generales}

De partida un hecho importante que se debe considerar es la trasformación histórica ocurrida con el concepto de humanidad, el cual encuentra su origen más remoto en la tribu y en los clanes, donde "el semejante" es justamente un miembro de la organización social a la que se pertenece; no en vano según Freud (1930) enemigo y extranjero fueron en algún momento conceptos idénticos. Conforme se trasforma la organización geo-política, del régimen feudal a las monarquías absolutas y posteriormente a los estados nacionales parlamentarios que traen consigo el advenimiento de la ciudadanía, se amplía notoriamente el concepto y reconocimiento del otro como semejante, inspirado también en los principios del cristianismo y en los ideales de la revolución francesa.

Por otra parte, la afiliación de los estados a organismos internacionales, generalmente en detrimento de su soberanía, la creciente interdependencia económica y una mayor comunicación y contacto entre los pueblos; así como la globalización de las crisis y de los conflictos financieros, políticos, militares y ambientales sólo para citar algunos y su correspondiente solución en el marco del multilateralismo, contribuyen hasta cierto punto al reconocimiento de la humanidad como una realidad planetaria. Correlativamente, a todos estos cambios el individuo pierde influencia y poder; cada vez existe una mayor opacidad y lejanía entre el individuo y un poder omnímodo y anónimo que parapetado en una estructura burocrática y legal se vuelve insensible y ajeno a las demandas y necesidades del sujeto.

Algo análogo ocurre con el concepto de subjetividad. Durante la antigüedad el destino estaba determinado por los dioses, en el medioevo la voluntad divina campeaba y sólo a partir de la modernidad se concibe la vida como una construcción humana y el tiempo se humaniza; en consecuencia el sujeto también se historiza y se ubica en determinadas coordenadas espacio-temporales a nivel personal y como género humano, siendo el concepto de sujeto hijo de la modernidad (Mo Sung, 2005).

Según Elias (2000), en las sociedades clásicas antiguas griega y romana no existía un concepto que designara al individuo en su significación actual, ya que los sujetos eran reconocidos por ser libres o esclavos, nobles o plebeyos, por su lugar de origen u oficios, antes que por sus características y cualidades personales, es decir, por su condición social. En el latín medieval individuo tenía la connotación de aquello que es inseparable e indivisible, posteriormente, con arreglo a la lógica formal, se utilizó para designar a un género u especie y diferenciarlo de otras, en el sentido de la especie humana. Con la escolástica se concibe que de todo cuanto existe es único, particular e individual, perfilando de esta manera un sentido más moderno al concepto. Posteriormente, durante el siglo XIX, a partir del auge de las ciencias sociales, el término individuo adquiere en lenguaje coloquial el significado contemporáneo de oposición a lo social o colectivo en lo que al ser humano se refiere.

Es importante considerar que las anteriores nociones de subjetividad parten históricamente del largo reinado del falogocentrismo; por tanto, alude a los hombres y no necesariamente a las mujeres, ya que son éstos quienes han ostentado la representación universal de la humanidad. Lo femenino ha sido concebido como la antípoda de lo masculino, su negación, de hecho el rival se denigra cuando se le asemeja a una mujer. (Martínez, 2007). La feminidad es el lugar de la carencia, de la falta, de la ausencia o de la atrofia; es un oscuro y oblicuo lugar que se teme. Diremos que históricamente la mujer ha sido una invención y fantasía masculina (Cardenal, 2012); empero, la hegemonía masculina se encuentra en crisis frente a los embates de las reivindicaciones feministas y de los cambios socio-culturales acaecidos, que ubican el papel de la mujer en la situación dilemática de continuar en el lugar histórico de la 
sub-alteridad, ocupar el lugar y función masculino masculinizándose en ese acto o construir un nuevo orden inclusivo pleno de respeto y equidad para todos (Bourdieu, 2000).

Históricamente, el sujeto se concibe a sí mismo como tal a partir del siglo XIX, cuando se visualiza como objeto de conocimiento en los albores de la psicología. Empero, para Foucault (2009) el interés y la preocupación respecto al sí mismo, está presente desde la antigüedad clásica europea tanto en los pre socráticos como en el propio Sócrates, siendo un antecedente histórico del ascetismo cristiano y del conocimiento filosófico de occidente, incluyendo a Descartes para quien la certidumbre y la verdad emergen a partir de la confirmación racional de la propia existencia del ser.

Por tanto, la historia del pensamiento occidental encuentra sus correlatos en la dialéctica del introspeccionismo y el objetivismo, ambas herederas de las antiguas tradiciones de pensamiento; siendo el sujeto capaz del conocimiento de sí y o del mundo por diversos caminos. A partir del racionalismo cartesiano adviene el sujeto de la modernidad o el sujeto de la ciencia tal y como lo llamó Lacan. Con la adscripción de la verdad al estatuto científico, el conocimiento no deviene ya como iluminación o salvación personal y se separan para siempre la ciencia y la teología, a partir de un emergente empirismo victorioso.

Existe, históricamente, una creciente división entre el orden natural y la realidad social, es decir lo no-natural, que no es estrictamente equivalente a anti-natural o contrario a la naturaleza. El ser humano vive una realidad simbólica que difiere de las leyes de la naturaleza, siendo, específicamente, humana. Ontológicamente, la realidad social que esta simbólicamente construida, adviene previa al sujeto y se constituye en una parte esencial de la identidad personal que determinará en él rasgos y características propias y compartidas, ubicándolo en determinados lugares y funciones siempre con consecuencias. Es, precisamente el divorcio existente entre el universo simbólico y el mundo material, lo que posibilita la emergencia del sujeto y su trascendencia de la realidad concreta.

\section{La determinación social del sujeto}

Para el marxismo (Marx, 2014) el sujeto se produce en las interacciones sociales que a la vez contribuye a constituir siendo objeto y sujeto de su propia transformación, a partir de lo cual, le corresponde una determinada conciencia como representación simbólica de la realidad social. Bajo la óptica marxista el sujeto está determinado por las condiciones histórico-materiales de existencia, de lo cual derivan formas concretas de organización social y las formas específicas de pensamiento y acción tributarias del orden social. El discurso dominante tenderá a mantener el estado de cosas produciéndose una lucha por la hegemonía en función de los intereses de clase, lo cual producirá, a partir de determinadas condiciones dadas un cambio en las estructuras sociales. El sujeto, así entendido, será el resultado de una experiencia y de una práctica social, valga decir de una "praxis", que lo constituye según sea su participación en la construcción de la realidad social.

El punto ciego de la teoría marxista consiste en que los procesos de acción-asimilación individualizada del contexto histórico-social que hacen del sujeto un ser diferenciado, esto es, semejante pero diferente a los demás, no son suficientes para explicar los procesos de individualización. Decir que la acción-asimilación individualizada acaece según sea la participación del sujeto en la construcción del mundo material, no da cuenta necesariamente de la estructura y de los procesos psicológicos implicados en la construcción de la subjetividad. El sujeto de la historia se agota en la materialidad social que le corresponde vivir, obviándose los procesos endo e intrapsíquicos que también dan forma y contenido a la experiencia y al ser subjetivo.

Asimismo, el materialismo histórico no tiene una noción de aparato psíquico que permita explicar cómo se organizan, funcionan y regulan los diferentes procesos psicológicos que animan al sujeto. En este punto es conveniente aclarar que dicha omisión no es necesariamente un defecto del portentoso edificio teórico marxista, el cual, se encuentra, de forma objetiva, más interesado en discernir las leyes que gobiernan histórica y materialmente el universo social, que en establecer las modalidades de 
apropiación subjetiva de la realidad. El materialismo histórico es una visión explicativa de la historia y no estrictamente del sujeto, que adviene como tal, en su condición de sujeto de la historia.

En todo caso la asunción de la producción histórico-cultural contribuye a perfilar las identidades sociales e individuales bajo la titularidad de "nosotros", integrando de esta manera a una comunidad simbólica de referencia, lo cual posibilita la comunicación e interacción. El otro, deviene en imagen especular, donde el sujeto se reconoce como tal, convirtiéndose a su vez en imagen especular donde los demás se reconocen a sí mismos. En tal sentido, el sujeto es el resultado de una alteridad que se produce en la interacción y el intercambio social que ocurre en determinadas condiciones histórico-sociales, de suerte que toda ontogénesis es por definición una sociogénesis. El sujeto así concebido es abierto, múltiple y diverso, con capacidades y posibilidades de incidir y transformar su entorno social y así mismo.

El ser de cada sujeto, aquello que lo constituye de una manera particular, tiene su origen en una exterioridad simbólica y discursiva previa al sujeto, que opera a partir de la inclusión de cada quien en el universo social. La socialización parte de la incorporación de una realidad simbólicamente preestructurada que tiene como correlato los modos sociales y culturales que moldean las subjetividades, brindando a la vez el marco regulatorio que posibilita el entendimiento y el intercambio donde los individuos se reconocen al mismo tiempo como semejantes y diferentes, de esta manera el sujeto se reconoce a sí mismo en la alteridad y en el vínculo con el otro. Los procesos de subjetivación surgen en el entramado social que se constituye en un referente de la identidad personal; sin embargo, los procesos de apropiación subjetiva difieren entre los individuos y su historia vital también, por lo cual, la acciónasimilación individualizada del contexto histórico-social y las contingencias particulares en las cuales acaecen, son inherentes a cada subjetividad (Martín-Baro, 2005).

Para Elias (2000), las elecciones y decisiones se ubican en el marco de los dominios estructurales en tanto posibilidades dadas, así mismo la concepción por parte del sujeto de escenarios emergentes y alternativos se desprenden necesariamente del orden social vigente, de manera tal que nunca una idea o pensamiento será absolutamente inédita. Los límites y grados de libertad estarán definidos según la época y organización social que se trate y según sea la ubicación y participación de cada sujeto en la estructura societal.

Las discursividades dominantes se cristalizan en decálogos religiosos, ideológicos, políticos o científicos que establecen formas y maneras de sentir, pensar y actuar brindando así un sentido de comunidad y estableciendo en este mismo acto los límites de lo otro. El sujeto asume como propias determinadas discursividades hegemónicas o alternativas, las cuales mediatizan las relaciones sociales y las modalidades personales (Martínez, 2007). Las relaciones y vínculos sociales acaecerán al tenor de las prescripciones y prohibiciones que dictan los órdenes establecidos siendo asumidos la mayoría de las veces al margen de la conciencia y de la acción crítica.

Las realidades simbólicas asentadas en determinadas prácticas sociales brindan una representación del mundo y de la vida bajo una óptica de obviedad y sentido común que prescinde de todo análisis y no requiere de constatación alguna (Martínez, 2014). El poder simbólico no se sostiene sin la participación de aquellos que somete a sus designios generalmente, de manera inconsciente. La representación del mundo ideológicamente inspirada según determinados intereses aparece bajo un halo de verdad y sentido común que prescinde de toda racionalidad y escrutinio quedando fuera de toda sospecha, que se confirma y reproduce en las estructuras y modos sociales a manera de un orden naturalizado.

Para Bourdieu (2000), la transmisión y reproducción del pensamiento dominante obedece a un sistema de estructuras inscritas en los cuerpos y las cosas, cuyo poder emana no tanto de una lógica argumental, sino de la reiteración misma que crea una condición dada, una especie de compulsión a la repetición inconsciente. Son esquemas de pensamiento, percepción, sensación y acción que se inscriben en las cotidianidades y en las subjetividades estableciendo a su vez verdades, certezas y creencias. El sujeto como tal es producido por ésta reiteración social, y sólo el deseo inédito rompe la armonía o mejor dicho la monotonía societal, rasgando la estructura social y el orden simbólico inherente. 


\section{El sujeto del inconsciente y la estructura social}

La acción-asimilación individualizada trasciende la historia previa de los vínculos, relaciones y experiencias del sujeto. Aún, cuando son de capital importancia en construcción subjetiva, no dan cuenta a cabalidad del acontecer personal. Es, ese resto, eso "otro" sin definir y cuyo origen y existencia generalmente se ignora pero que está omnipresente en nuestros anhelos, pensamientos y acciones, lo que brinda un cariz personal, único y particular que caracteriza el ser de cada quien. No se trata de una esencia o de una sustancia al margen de la realidad social, se trata más bien de aquello que la sociedad y la cultura proscribe y que emerge como un poderoso deseo, el cual, por imperio de la represión (que siempre tendrá un origen cultural) retorna como inconsciente. El sujeto del inconsciente es la tercera afrenta que como humanidad padecemos, la cual se suma al heliocentrismo copernicano y al evolucionismo darwiniano según lo propuso el propio Freud.

Si para el marxismo el cometido histórico del ser humano es someter las fuerzas ciegas de la naturaleza, para el psicoanálisis la naturaleza que hay que dominar, no es el mundo circundante, sino la propia naturaleza interna que la cultura como fin supremo intenta someter (Freud, 1913/2012). Los mandamientos culturales son impuestos originalmente a través de la coerción; sin embargo, verbigracia del mecanismo de la introyección dichos mandamientos culturales son asumidos como propios, desplazándose del locus externo al locus interno, valga decir, al autocontrol. Esto crea la ilusión de que sé es el artífice de los propios valores, conceptos e ideas, cuando en realidad la génesis de estos son el resultado de dinámicas y tensiones sociales y de su ulterior asimilación por parte del sujeto.

Los intercambios sociales por su parte, independientemente de sus características, son de naturaleza consciente e inconsciente y se conjugan de cierta manera en las interacciones subjetivas, lo cual contribuye a moldear los comportamientos, relaciones y vínculos sociales que definen la vivencia y la convivencia. Por otro lado, es importante que mencionar la tradición patriarcal performativa heredera de la tradición judeo-cristiana, se continúa reproduciendo en el capitalismo tardío, las inobjetables conquistas sociales de las minorías y de las mayorías; como en el caso de las mujeres, son asumidas y reconfiguradas a imagen y semejanza del sistema sin alterar muchas veces la naturaleza del mismo, aunque constituyen importantes avances en pos de la equidad y la justicia social.

Para Freud, la unidad de análisis fundamental es el individuo, esto es, las experiencias, vivencias, anhelos y frustraciones de cada quien en su entorno más inmediato, y no tanto la contextualidad histórico-social que le corresponde vivir. El individuo, psicoanalíticamente entendido (Freud, 1930/2012), es el origen del movimiento social y no lo contrario, el cometido de la cultura es aplacar y dominar la emergencia pulsional, imponer la denegación del deseo y facilitar su realización sublimada. Existe para Freud una naturaleza humana intrínseca e invariable que más allá de los avatares históricos persiste, siendo la historia tan sólo el telón de fondo donde se desarrolla una dramaturgia sempiterna vuelta sobre sí misma; de esta forma, el ser humano está condenado a sufrir por siempre -preso de sus deseos- los mismos complejos y ansiedades producto de una renuncia primordial, a manera de un tributo por vivir en sociedad. A diferencia del marxismo, para el psicoanálisis existe un individuo mítico previo a la negación de su deseo y anterior a la sociedad y a la cultura.

El psicoanálisis abandona la racionalidad imperante allende de la filosofía y sus sistemas (Badiou, 2010); en sus orígenes se encuentra la mirada médica del Freud fisiólogo y neurólogo, del pathos entendido no sólo como enfermedad, sino en su sentido antiguo (epicurio y estoico) como "pasión", que era realmente lo que aquejaba a las pacientes histéricas de Charcot, Breuer y del propio Freud. Sin embargo, también se aleja de la ciencia al sustentar el tema de la veridicción que ya no reposa en la realidad fáctica y el dato que le hablan al sujeto desde el lugar de la evidencia, sino de un sujeto que cuando habla dice una verdad que subyace en él, pero que él mismo ignora.

El psicoanálisis en tanto verdad enunciada por un sujeto que la ignora, realiza un viraje de la racionalidad moderna e invierte el estatuto de la realidad que ya no subyace en el mundo circundante y sus objetos, sino en una interioridad que como fuente de verdad y validación de sí mismo. Esta verdad 
siempre elusiva le concierne sólo al sujeto y mantiene su estigma y propósito original al margen de la conciencia y circunstancias de éste, determinándolo; el conocimiento de sí será entonces parcial y borroso de manera tal que siempre queda un resto por elucidar. Por esta vía el psicoanálisis rompe con la introspección al perder ésta el carácter de una mirada racional sobre el propio acontecer y de la verdad como iluminación dada a manera de gracia o como un origen divino que habita en nosotros mismos.

El psicoanálisis funda un método de conocimiento diferente cuyo propósito expreso es eludir la conciencia y abstraerse de toda racionalidad, a la vez que prescinde de lo que, parafraseando a Foucault (2009), podríamos denominar como "tecnologías" del espíritu, tales como: la meditación, el recogimiento, el claustro, el rito, el ayuno o la mortificación del cuerpo que urden su origen en la antigüedad clásica y son asumidas por la tradición cristiana como formas de purificación y trascendencia, sin olvidar la otra vertiente de la salvación que consiste en el amor y el servicio al prójimo. A partir del psicoanálisis se construye un objeto de estudio inédito en la historia, el sujeto del inconsciente y se construye una nueva ontología y epistemología.

Desde una perspectiva psicoanalítica existe una particular preponderancia hacia los fenómenos del inconsciente, en lo que a la constitución de la subjetividad se refiere. Para Johnston (2010), ningún sujeto es posible sin la constitución de un inconsciente el cual se establece como un límite último donde se refugia la subjetividad a manera de "lo inédito del inconsciente". La vida pulsional brinda siempre un margen de libertad que posibilita una expresión singular de la subjetividad, que la diferencia y hace socialmente reconocible.

La existencia de lo inconsciente es una suerte de mácula que denuncia una ausencia en el orden racional, un agujero que no se comprende ni explica desde una perspectiva lógica ni desde el discurso oficial que intenta obturarlo. Es el par antitético de la estructura social y a la vez su razón de ser, es la negación de la negación (Huson, 2010). Es del orden de lo proscrito, de lo in-nombrado y de lo forcluido socialmente, un deseo inadmisible que desafía la realidad. Una verdad que se encuentra más allá de la conciencia, de lo simbólico y de la palabra aunque sólo puede ser aprendida verbigracia del lenguaje, no a partir de lo que se dice sino de lo que se obvia o se niega, de aquello otro que se omite, pero que es necesario a-palabrar. Es el reverso, el otro sentido, una segunda mirada que descubre una nueva perspectiva. No se trata de una ideología, tampoco de un discurso alternativo que encontrarán siempre sus linderos en el discurso dominante, siendo un discurso acerca del discurso dominante, tampoco de la conciencia que se pueda tener de la enajenación o de los procesos de subjetivación donde ésta acaece.

La noción del inconsciente como un "acontecimiento social", tiene que ver con lo proscrito y excluido culturalmente desafiando de esta manera la realidad social, al oponerse a los dictados y mandamientos sociales. El inconsciente así entendido se constituye en el punto de confluencia entre el individuo y la cultura, en el espacio donde se encuentran aquellas realidades culturalmente negadas con los deseos prohibidos del individuo que buscarán su realización de manera sublimada o no. Es, precisamente, en este intersticio donde emerge el sujeto que será por siempre un sujeto de deseo. La subjetividad concebida de esta manera, se escurre entre los intersticios de la red simbólica y sus determinantes, aun cuando se exprese en sus términos; es la novedad y "lo otro" resultado de una ruptura momentánea en el sistema de significados. Bajo esta perspectiva, la hermenéutica de orientación psicoanalítica se propone como enlace entre el hecho y la experiencia, el dato y la representación, la realidad y el deseo; lo cual posibilita establecer relaciones de sentido entre estos órdenes constructores de realidades sociales y subjetivas (Martínez, 2014).

\section{Más allá de lo social}

Lo que Lacan llamara “el Otro” implica las normas simbólicas (Žižek, 2011) que en su condición de tales contienen las prescripciones y prohibiciones a observar, tanto en el universo social como en el fuero interno, siendo así una parte constitutiva de la subjetivad. La otredad se erige como amo supremo 
que dicta y define y cuya aceptación normativa es mandamiento para el sujeto, su desafío se paga con el ostracismo y el escarnio social.

Lo Otro no tiene dueño, es ingobernable y la posibilidad de control es tan sólo un vano afán neurótico; lo cual no niega la existencia a nivel histórico-social de hegemonías, contradicciones y pugnas intestinas de poder. El amo es tal en función del reconocimiento de quienes confirman su estatus, sin dicho reconocimiento no existiría, su poder es especular y se sostiene en tanto representa simbólicamente los intereses de sus adeptos, de allí que el ejercicio de la coerción sea directamente proporcional a la pérdida de su representatividad. El imperativo del deseo no sólo juega en el más allá de la estructura y de las discursividades contestatarias, también juega en la ideología dominante y demás ideologías que para ser operativas (Žižek, 2011), deben reconocer los anhelos de aquellos que somete a su designio, sin que esto signifique que tales anhelos sean legítimamente representados. Una de las características fundamentales de la ideología es hacer aparecer como propios los intereses ajenos en un claro movimiento de ocultación, tergiversación y favorecimiento.

Para Žižek (2011), el sometimiento al poder tiene una dimensión y retribución libidinal más allá de la coacción. En las imposturas ideológicas o la fuerza del denominado hábitus (Bourdieu, 2010), existe una especie de erotización del poder, una suerte de goce sadomasoquista que se alía al statu quo. La autoridad del amo reside en el deseo del otro que le constituye a imagen y semejanza de su deseo y en la esperanza de su realización. En una suerte de histerización el deseo del amo es el deseo del otro, razón por la cual este circuito sólo se pude cortar a partir del reconocimiento del deseo como propio.

El lenguaje, por su parte, establece una relación entre las palabras como atributo del sujeto y el mundo como condición dada, a su vez facilita el intercambio a partir del consenso comunicacional. El sujeto es siempre un sujeto del discurso que le antecede y constituye performativamente, aún cuando éste se asume como el artífice de "sus propias" palabras e ideas, sin darse cuenta que le son dadas.

Los discursos dominantes se constituyen a manos del poder en un poder/saber y en un saber/ poder que propenden al control de la conciencia y de los cuerpos también. El control tiene su origen en una exterioridad que se interioriza y se re-constituye en "autocontrol", alimentando la fantasía del libre albedrío (Martínez, 2005). Lo característico del sujeto es la producción de un discurso propio que es su contribución al discurso social, el cual se encuentra enmarcado en los límites de éste, a la vez que lo trasciende. El lenguaje como tal no agota las inconmensurables posibilidades de la realidad que escapan a la representación simbólica, queda siempre un residuo innombrable (no proferido) a manera de lo inédito del sujeto.

La universalidad que caracteriza al capitalismo tardío, es una universalidad vacía donde los individuos se sienten convocados y a la vez excluidos, donde las demandas particulares se diluyen, estandarizan y uniforman. El reconocimiento oficial de las discursividades alternativas, constituye la muerte de las mismas. Las lógicas de resistencia se incuban en el ámbito del poder, siendo el discurso contestatario un discurso acerca del discurso dominante, se refiere a sus términos y lo interpela desde su lógica subyacente, estableciéndose como una alternativa a éste aunque no distinto de éste (Martínez, 2014). Lo anterior, no significa que el sistema no pueda colapsar a partir de sus propias contradicciones internas, contradicciones que son encarnadas también por los propios sujetos.

En el capitalismo tardío, el sujeto sigue siendo objeto de represión, aunque a partir de la declinación edípica del padre los viejos recursos de contención super-yoica y del temor a su autoridad pierden eficacia, lo propio se puede decir de los discursos políticos y religiosos de diversa índole, inspirados precisamente en los mandamientos paternales. Emerge entonces una nueva moralidad, supuestamente, inspirada en la universalidad de los derechos humanos, de las naciones, los animales y de la propia naturaleza, universalidad que no implica en ningún caso igualdad ni tampoco libertad, siendo por contrapartida una imposición y una justificación ideológica para el ejercicio del poder. La coacción es directamente proporcional a la resistencia, cuando un cierto exceso de presión sobrepasa el ámbito de tolerancia que soporta el sistema, se requiere de una mayor actividad represiva que se ejercerá en lo jurídico, político y como violencia institucionalizada. 
La pertenencia a una estructura social a partir una realidad "multicultural", "incluyente" y "diversa" provoca el desvanecimiento de la diferencia, la equiparación y la pérdida de la individualidad; lo que nos deja frente a un universo omnímodo que impone una aceptación incondicional, de manera que, todo aquello que se separe y diverja es paradójicamente excluido. La inclusión se paga con una aceptación a-crítica de la estructura social y sus modos, con la globalización del sujeto y su des-personalización. La multiculturalidad parte de una pretendida neutralidad objetiva que impone los valores e intereses particulares como universales, arrogándose su tutelaje. El libre flujo del capital es el límite último que enfrenta la subjetividad en las sociedades contemporáneas, constituyéndose a su vez en el punto de fractura.

En medio de las modas que como tendencias dicta el sistema, subsiste un individuo colonizado, mediatizado y normatizado carente de utopías y atrapado en redes de significación predeterminadas que le son impuestas y a las cuales obedece ciegamente, es el mundo del ciber-salvajismo del que habla Quirce (2014). En este escenario la demanda subversiva suele ser subsumida por el sistema y termina siendo parte de éste, de ahí su casi infinita capacidad de mutar. En todo caso, las grandes y pequeñas reivindicaciones movilizan las estructuras en determinados sentidos, siendo, generalmente, un factor dinamizante. Las grandes transformaciones acaecen cuando los límites del sistema son rebasados, produciéndose una suerte de implosión que da por resultado una nueva configuración social.

Siguiendo a Žižek (2011), se puede decir que cada vez es más complejo articular las reivindicaciones al interior de un mega-proyecto político-social que logre concertar distintas voluntades. Las grandes edificaciones teóricas y proyectos histórico-sociales dan paso a teorías de mediano y corto alcance más interesadas en aspectos empíricos, funcionales e instrumentales, que a una explicación comprensiva de la realidad.

Cabe preguntarse a esta altura: ¿qué es realmente lo que se oculta detrás del orden social imperante, acaso la ruptura, el punto ciego, la ausencia del orden simbólico o aquel intersticio donde se teje la subjetividad más allá de la determinación social?, ¿qué es ese resto elusivo que se escapa a la designación?, ¿En qué consiste y cuál es su función? Estas interrogantes han sido respondidas de múltiples maneras bajo la titularidad de lo innombrable, lo real, el sujeto del inconsciente y la nada. Se hace alusión, en todo caso, a aquel espacio ausente de estructura y de la estructura que escapa al orden simbólico, donde el sujeto se encuentra merced del sí mismo allende al orden social, de allí su carácter inédito y transformador a nivel societal.

Parafraseando a Buck-morss (2011), se puede decir que la verdad es siempre relativa e histórica, pero aunque toda verdad es histórica, la historia no da cuenta de la verdad. Tal atribución sería asignarle un carácter metafísico a la historia. De ésta forma el sujeto histórico enunciado así, de manera singular, es siempre una abstracción porque en la realidad concreta lo que existe son sujetos semejantes y diferentes entre sí, sujetos de la historia, de su propia historia y de una singularidad propia. La subjetividad no es una materialización concreta, es una potencialidad que se concreta en un intersticio del tiempo y el espacio en función de una construcción colectiva mediada por la convergencia del conjunto de las relaciones sociales, políticas, económicas y también de las experiencias personales que constituyen al sujeto.

El estatuto de verdad ciertamente no sólo es un asunto histórico o epistémico, ya que alude al sujeto quien en última instancia será donde reside la verdad. Desde una perspectiva ontológica, el tamiz de la subjetividad se vuelve esencial para el discernimiento de la verdad, ya que el sujeto cognoscente es portador de una historia y de su propia historia, perteneciente a una determinada cultura y clase social que carga consigo determinadas ideas, valores, creencias y prejuicios; así mismo, está conformado a partir de ciertas características y condiciones psíquicas únicas e irrepetibles en cada momento histórico, todo lo cual incidirá de manera decisiva en la "admisión" de la verdad.

Desde una perspectiva psicoanalítica, la verdad no sólo es evasiva en función de su falsa apariencia, también el propio sujeto le opone resistencias y se engaña a sí mismo preso de sus deseos y ansiedades; a este efecto, es importante recordar la paradoja del sujeto de la elución, que dice a la letra: "Yo siempre miento". 


\section{El sujeto de la fisura estructural}

Según Martínez (2014), la constitución de la subjetividad se debate entre los monismos estructuralistas, logocéntricos y del sujeto del inconsciente. Distintos autores, sostienen que a partir de la ruptura de la estructura social emerge el sujeto, el cual no se caracteriza por ser una sustancia ni esencia alguna. Lo subjetivo es lo inédito en la constelación social, una huella y marca diferencial que se instala en una vacuidad que el entramado social no puede obturar. Surge de una demanda que denota una ausencia, una carencia y una falta de naturaleza inconsciente que tiene consecuencias para el sujeto y para la propia estructura social. Es un deseo que desea una satisfacción imposible.

Según Hinkelammert (1996), el sujeto es una ausencia que grita y resiste la dominación del sistema social, por tanto, es utopía, trascendencia y realización. Sin embargo, el anhelado reino de la libertad es tan sólo un esquivo horizonte en pos del cual se emprende la marcha a ese imposible lugar, y es en esta incesante búsqueda donde reside la posibilidad transformadora del sujeto respecto de sí mismo y de su realidad. Las utopías sociales nunca podrán satisfacer el deseo, que siempre posará su mirada más allá, forzando, de esta manera los horizontes.

El sujeto emerge en el intersticio entre la estructura y lo real, es imposible de simbolizar y de estructuralizar (Bosteels, 2010). La carencia es inherente a la propia incapacidad de contener, en un sentido estructural, toda la producción de la subjetividad y de ubicarla per se en el registro de lo simbólico. Algo queda y algo se va, ese exceso imposible de simbolizar que escapa a la estructura social deviene en lo inédito del sujeto. El sujeto emerge a manera de una interrogación frente a la estructura, que para todos los efectos, es siempre social.

La subjetividad surge a partir de un imposible espacio que se abre momentáneamente entre el sujeto y la estructura social donde éste habita, es una aportación inédita, un acontecimiento (Žižek 2012), esto es, algo imprevisible en una situación dada, que brinda una escapatoria circunstancial y permite dejar una marca diferencial y singular la cual separa y a la vez integra al sujeto al todo social. Para Bosteels (2010), el sujeto es una fisura entre lo real y la imposibilidad de su simbolización al interior de la estructura social, tal y como lo plantea Žižek (2011), el sujeto es correlativo a su propia imposibilidad y carencia.

Inubicable, inaprensible e indescifrable, esta causa ausente evanescente se encuentra omnipresente en el orden social establecido, contribuyendo a perfilar sus contornos históricos y culturales, sólo apreciable bajo la faz de la novedad de aquellos acontecimientos que marcan nuevos derroteros, a partir de un excedente que se cola en la estructura social y que termina materializándose en ella, inicialmente en condición de alteridad para posteriormente formar parte del estado de cosas, en un movimiento perpetuo y siempre cambiante (Bosteels, 2010).

Para Žižek (2011), Lacan responde a la pregunta ontológica: ¿Porque existe algo en lugar de la nada?, a partir del vínculo que establece entre la existencia y el goce. La existencia es siempre incompleta re-creándose perpetuamente y siempre por hacerse; el goce es el lugar propio del sujeto que posee como característica fundamental la histerización, que le vuelve siempre carente y siempre deseante. El goce es una aberración ontológica, un sesgo en la existencia que se percibe necesariamente de una manera espectral y pre-ontológica.

Ese exceso inaccesible e inconcebible que habita en el sujeto se ubica más allá de las posibilidades de realización de toda subjetividad y escapa a las condiciones histórico-materiales de su concreción, siendo del orden del anhelo y por ende de lo no realizado. Sus dominios se ubican en los linderos de las fantasías, ficciones, mitologías y religiones, a manera de una realización sustitutiva, siempre incompleta. La totalidad perdida y su vana promesa de realización encuentran su correlato en la versión psicoanalítica del estado de nirvana (Freud, 1914/2012), que remite a un momento primordial de plenitud, cuyo retorno es imposible, aunque se añora por siempre.

Con la ruptura que epistemológica que implica el psicoanálisis, se regresa en cierto sentido a un momento primordial de la humanidad donde el mito es fuente y estatuto de conocimiento, previo a la 
entronización en la antigüedad clásica occidental del pensamiento racional-especulativo que dirige su mirada al mundo físico y a las relaciones de causa y efecto. La visión mítica y religiosa es identidad individual y colectiva que cumple una importante función psíquica y social, a la vez que define los límites y fronteras de los contornos societales.

Los sueños, las fantasías, el arte, los mitos y leyendas conforman una región intermedia donde se encuentran el deseo con las posibilidades manifiestas de su expresión, a partir de lo cual, el material inconsciente asume una gramática y una semántica que permite su intelección analítica. El mito retorna a su condición esencial de explicación primera y última del mundo y de la vida, aunque sin la ingenuidad original que le caracterizó, porque el mito para Freud no es una verdad enunciada, sino una verdad velada que es necesario desentrañar; es una construcción social sustentada en una vivencia óntica que remite a un deseo colectivo y prohibido de naturaleza filogenética, que encuentra en parte su realización en la propia dimensión mítica y en la fantasía (Martínez, 2012).

En la mitología freudiana con el homicidio primordial del padre totémico a causa de los celos y concupiscencia de sus hijos, deviene el Dios-padre de la ley que a diferencia del padre gozoso totémico cancela el goce para sí y lo pospone (al menos en la tradición judeo-cristiana) para sus hijos, ubicándolo, en un nivel supra-terrenal a cambio de obediencia y adoración (Freud, 1913/2012). Dios es hijo de las falencias y necesidades humanas así como del deseo de trascender, una manera de llenar la inconmensurabilidad y derrotar la incertidumbre y la muerte, brindando de esta forma esperanza y consuelo. La necesidad de Dios es del inédito del inconsciente, una condición inherente y consustancial al propio ser, de manera tal que queda siempre el recurso de negar, sobre todo en tiempos de penurias, el abismo inconmensurable que se abre frente a la propia impotencia y finitud, apelando al Dios omnipotente. Dios no es un concepto, tampoco una idea, es una experiencia de plenitud frente a la vacuidad interna.

Existe una suerte de teologización que intenta obturar esta vacuidad inescrutable con contenidos religiosos, filosóficos y políticos, que dan paso a las grandes utopías y edificaciones teóricas, en un afán de imponer un sentido y un orden neurótico en el caos original. Se inventan de esta manera verdades destinadas a prevalecer sobre todas las demás, estableciéndose así una competencia en la "libre concurrencia" de paradigmas, ideologías y religiones también. La plenitud de la vacuidad jamás se podrá llenar a partir de tales constructos sociales, y los nuevos órdenes imaginables e inimaginables serán siempre horizontes utópicos inalcanzables, aunque proveen un sentido de orientación en pos de los cuales se mueven las subjetividades y los propios sistemas sociales, sin llegar a realizarse como tales.

La historia escribe sus páginas más sobresalientes, allí, donde se quiebra la estructura frente a la irrupción del acontecimiento colectivo, que no es arbitrio sino consecuencia, aunque no siempre deliberada, por parte de los sujetos. No hay que perder nunca la perspectiva de que un acontecimiento emerge en determinadas circunstancias histórico-sociales específicas, razón por la cual, se encuentra de alguna manera signado por éstas. La emergencia del acontecimiento transforma las condiciones históricosociales e impacta las subjetividades. De esta manera, el sujeto sufre la impronta del acontecimiento en cuestión, siendo también transformado por éste.

\section{Bibliografía}

Badiou, Alain. (2010). Lacan y los presocráticos. En: Žižek, S (ed). Lacan Los Interlocutores Mudos. Madrid: Ediciones Akal. S.A.

Bosteels, Bruno. (2010). La teoría del sujeto de Alain Badiou: el reinicio del materialismo dialéctico En: Žižek, S. (ed). Lacan Los Interlocutores Mudos. Madrid: Ediciones Akal. S.A.

Bourdieu, Pierre. (2000). La dominación masculina. Barcelona: Editorial Anagrama.

Buck-morss, S. (2011). Origen de la dialéctica negativa. Buenos Aires: Eterna Cadencia.

Cardenal, Tatiana. (2012). Ese cuerpo que no es de uno. La sexualidad femenina en Luce irigaray. Thémata. Revista de Filosofía No 46 (1), 353-360.

Elias, Norbert. (2000). La sociedad de los individuos. Barcelona: Ediciones Península. 
Freud, Sigmund. (1913/2012). Tótem y Tabú. Obras completas. Tomo 2. Madrid: Editorial Nueva Biblioteca.

Freud, Sigmund. (1914/2012). Introducción al narcisismo. Obras Completas. Tomo 2. Madrid: Editorial Nueva Biblioteca.

Freud, Sigmund. (1930/2012). El malestar en la cultura. Obras Completas. Tomo 2. Madrid: Editorial Nueva Biblioteca.

Foucault, Michel. (2009). Hermenéutica del sujeto. Buenos Aires: Fondo de Cultura Económica.

Hinkelammert, Franz. (1996). El mapa del emperador. Determinismo, caos, sujeto. Recuperado de ///C:/ Users/Mfile:anuel/Downloads/Mapa\%20emperador.pdf [Consulta13 ene. 2016].

Huson, Timothy. (2010). Lacan y los presocráticos. En: Žižek, S. (ed). Lacan Los Interlocutores Mudos. Madrid: Ediciones Akal. S.A.

Jhonston, Adrian. (2010). Fantasmas del pasado de las sustancias: Schelling, Lacan y la desnaturalización de la naturaleza. En: Žižek, S. Lacan Los Interlocutores Mudos. Madrid: Ediciones Akal. S.A.

Martín-Baro, Ignacio. (2005). Entre el individuo y la sociedad. En Acción e ideología. Psicología social desde Centroamérica. San Salvador: UCA Editores.

Martínez, Manuel. (2005). Subjetividad y cultura, una mirada freudiana. Reflexiones. 84 (2), 61-70

Martínez, Manuel. (2007). Claves para una mayor comprensión entre la subjetividad y la cultura. Por I. Dobles, S. Baltodano, V. Leandro. Psicología de la liberación en el contexto neoliberal. (163-167) San José: Editorial de la Universidad de Costa Rica.

Martínez, Manuel. (2007). La construcción de la feminidad: la mujer como sujeto de la historia y como objeto de deseo. Actualidades en Psicología 21, 79-93

Martínez, Manuel. (2012). Análisis hermenéutico profundo acerca de la en la leyenda "La Segua": el caso de la obra de Alberto Cañas. (Tesis de Doctorado en Estudios de la Sociedad y de la Cultura). Universidad de Costa Rica.

Martínez, Manuel. (2014). Constitución de la subjetividad. Reflexiones psicogenéticas. San José: Editorial UCR.

Marx, Karl y Engels, Friedrich. (2014). La ideología alemana. Madrid: Akal.

Mo Sung, Jung. (2005). Sujeto y Sociedades Complejas: para repensar los horizontes utópicos. San José: DEI.

Quirce, Carlos. (2014). Reflexiones psicológicas y filosóficas sobre una nación en crisis. San José: EUNED.

Žižek, Slavoj (2011). El espinoso sujeto. Buenos Aires: Editorial Paidós.

Žižek, Slavoj. (2011). El ocaso de las fantasías. Madrid: Ediciones Akal, S. A.

Žižek, Slavoj. (2012). El sublime objeto de la ideología. Buenos Aires: Siglo Veintiuno Editores. 
